\title{
Metastatic Breast Carcinoma with Treatment- Resistant Hypocalcemia
}

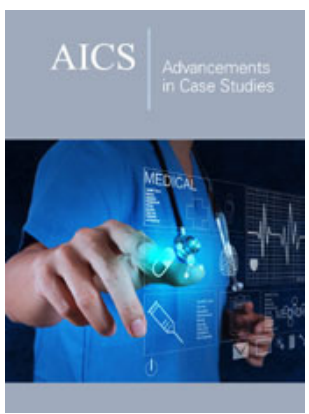

*Corresponding author: Serhat Özçelik, Adiyaman University Training and Research Hospital, Endocrinology and Metabolism Clinic, Adiyaman, Turkey

Submission: 侮February 25, 2019

Published: 眥 March 11, 2019

Volume 1 - Issue 5

How to cite this article: Serhat Ö, Ferhat F, Mehmet Ç, Melike Ö, Süleyman B, et al. Metastatic Breast Carcinoma with Treatment-Resistant Hypocalcemia. Adv Case Stud.1(5). AICS.000523.2019.

DOI: 10.31031/AICS.2019.01.000523

Copyright@ Serhat Özçelik, This article is distributed under the terms of the Creative Commons Attribution 4.0 International License, which permits unrestricted use and redistribution provided that the original author and source are credited.

\author{
Serhat Özçelik ${ }^{1 *}$, Ferhat Ferhatoğlu², Mehmet Çelik ${ }^{1}$, Melike Özçelik ${ }^{3}$, Süley- \\ man Baş ${ }^{2}$, Hasret Cengiz ${ }^{1}$ and Hüllya Ilıksu Gözü ${ }^{4}$ \\ ${ }^{1}$ Department of Haydarpaşa Numune Education and Research Hospital, Turkey \\ ${ }^{2}$ Department of Haydarpasa Numune Education and Research Hospital, Turkey \\ ${ }^{3}$ Department of Adıyaman University Training and Research Hospital and medical oncology, \\ Turkey \\ ${ }^{4}$ Department of Marmara University Faculty of Medicine Education and Research Hospital, \\ Turkey
}

\begin{abstract}
Introduction: Hypocalcemia is a condition that can occur in malignant diseases due to tumor lysis syndrome or chemotherapy agents. Hypocalcemia due to hypoparathyroidism accompanying malignancy is very rare. We, in this report are sharing a case of metastatic breast carcinoma with treatment -resistant hypocalcaemia.
\end{abstract}

Case Report: A 37-year-old woman who was diagnosed and followed-up with panhypopituitarism and contractions throughout the body after a recent child delivery. On the basis of the positive chvostek and trausseu findings on the physical examination of the patient we did hypocalcemia work-up and found plasma calcium: $5.4 \mathrm{mg} / \mathrm{dl}$, phosphorus: $7.8 \mathrm{mg} / \mathrm{dl}$, albumin: 4g/dl, $25-\mathrm{OH}$ vitamin D3: $18.7 \mathrm{ng} / \mathrm{ml}$ and parathormone as $<3 \mathrm{pg} / \mathrm{ml}$. Considering primary hypoparathyroidism, calcium carbonate and calcitriol treatments were applied. However, ca-gluconate infusion was initiated on the basis that calcium levels remained at $6.5 \mathrm{mg} / \mathrm{dl}$. In the cranial-pituitary MRI examination there were multiple millimetric nodular lesions of in cerebral and cerebellar hemispheres. PET/CT revealed a hypermetabolic area of malignant character in the lower quadrant of the left breast which can represent the primary tumor and multiple hipermetabolic areas in axial skeleton showing the most prominent activity in C2 and T6 vertebra. The biopsy result from the mass in the breast was reported as invasive lobular carcinoma and the patient was referred to the oncology department.

Discussion: Hypoparathyroidism may develop due to surgery, autoimmune or destruction in the parathyroid gland. The cause of hypoparathyroidism, which further complicated the treatment of hypocalcemia in our patient, may be due to metastasis or to the possible autoimmune mechanisms or PTHrP. Osteoblastic metastasis and PTHrP may have been found at the same time, and this cycle may have shifted towards osteoblastic activity. We can't find any association between breast cancer and autoimmune hypoparathyroidism in the literature.

Conclusion: Although there are other reasons that complicate the clinical status in treatment-resistant hypocalcemia patients, it should be considered that there may be an underlying malignancy.

\section{Introduction}

Hypocalcemia is a condition that can occur in malignant diseases due to osteoblastic bone metastasis, tumor lysis syndrome or chemotherapy agents [1]. However, hypocalcemia due to hypoparathyroidism accompanying malignancy is very rare [2]. Clinical presentations of cancer patients may develop depending on the local and paraneoplastic effects of the tumor and the immunological response to the tumor. We, in this report are sharing a case of metastatıc breast carcinoma with treatment -resistant hypocalcaemia.

\section{Case Report}

A 37-year-old woman who was diagnosed and followed-up with panhypopituitarism at an external center, admitted to our emergency polyclinic with complaints of hand and foot numbness, and contractions throughout the body after a recent child delivery. On the basis 
of the positive chvostek and trausseu findings on the physical examination of the patient we did hypocalcemia work-up and found plasma calcium: $5.4 \mathrm{mg} / \mathrm{dl}$, phosphorus: $7.8 \mathrm{mg} / \mathrm{dl}$, albumin: $4 \mathrm{~g} / \mathrm{dl}$, $25 \mathrm{OH}$ vitamin D3: $18.7 \mathrm{ng} / \mathrm{ml}$ and plasma parathormone as $<3 \mathrm{pg} / \mathrm{ml}$. Considering primary hypoparathyroidism, oral calcium carbonate and calcitriol treatments were applied in addition to the current steroid and levothyroxine treatment. However, iv. calciumgluconate infusion was initiated on the basis that calcium levels remained at $6.5 \mathrm{mg} / \mathrm{dl}$ despite calcitriol $3.5 \mathrm{~g} /$ day and calcium carbonate $3 \mathrm{x} 4 \mathrm{~g} /$ day. During hospitalization, analyses done as a result of abdominal pain and transaminase elevation occurence, +2 positive antinuclear antibody in serology and lymphocytedominant mild portal inflammation on hepatic biopsy was detected.

The case was compatible with autoimmune hepatitis. In the cranial and pituitary MRI examination of the patient on high dose calcium and vitamin D treatment and with stable serum calcium levels, infundibulum thickness, multiple millimetric nodular lesions of about $6 \mathrm{~mm}$ in diameter in cerebral and cerebellar hemispheres and the brain stem. In the clivus, instead of the expected normal osseous tissue signal, a mass localized in medullary region, composing the majority of the clivus with heterogeneous signal contrast enhancement was observed. The patient was investigated for malignancy. No features were seen in the examination of both breasts. Mammography and breast ultrasonography were ended up with fibrocystic breast pattern and categorized as BIRADS 2 PET/CT revealed a hypermetabolic area of malignant character in the lower quadrant of the left breast which can represent the primary tumor and multiple hipermetabolic areas in axial and appendicular skeleton showing the most prominent activity in C2 vertebra, corpus sterni and T6 vertebra. The biopsy result from the mass in the breast was reported as invasive lobular carcinoma with pleomorphic type and the patient was referred to the oncology department for follow-up and treatment.

\section{Discussion}

Breast cancer is the second leading cause of cancer-related deaths in women in developed countries and is the most common cancer-causing death in women worldwide [3]. The most common subtypes of breast cancer are invasive ductal carcinoma (IDC) and invasive lobular carcinoma (ILC). ILC is in second place by frequency after IDC, and atypical metastatic sites have been reported in patients [4]. Hypoparathyroidism may develop due to surgery, autoimmune or genetic causes that cause destruction in the parathyroid gland. Surgery done for thyroid diseases is the most common reason [5].

Those of autoimmune origin tend to be more permanent and may present as part of other endocrine disorders. Treatment resistant hypocalcemia may be seen in magnesium deficiency, postoperative hypoparathyroidism, utilization of calcium-deprivation agents in bone like bi-phosphonate and denosumab, autoimmune hypoparathyroidism and malignancies that cause osteoblastic bone metastases such as prostate and breast cancer [1,6-8]. Magnesium levels were normal in this patient. In our patient, the onset of symptoms was explained with severe hypocalcemia due to primary hypoparathyroidism, and the diagnosis was made as metastatic breast carcinoma in the course of follow-up and treatment. Bone metastasis of malignancies is most often described by the hypothesis of 'seed and soil', which is related to both the characteristics of the tumor cell and the microenvironment of the bone tissue [9]. Among the mediators that explain osteoblastic mechanisms are ET-1, BMPs, UPA, PSA and TGF-B, which are particularly associated with prostate cancer [10]. The accompanying hypoparathyroidism has made treatment difficult. The cause of hypoparathyroidism, which further complicated the treatment of hypocalcemia in our patient, may be due to metastasis or to the possible autoimmune mechanisms or PTHrP. Many tumors that metastasize to the parathyroid gland have been identified, with breast cancer being the most common with an incidence of $40 \%$. However, we could not find an additional mechanism in the literature other than invasion or metastasis to parathyroid gland that may cause hypo functioning. There was no histopathologic evidence of metastasis to the parathyroid gland in our patient and we did not find any involvement in PET/CT that would suggest this as well. In our case, osteoblastic metastasis and PTHrP may have been found at the same time, and this cycle may have shifted towards osteoblastic activity. Subsequently added to the clinical picture, the hepatitis and ANA positivity were resulted us leading to autoimmune-induced syndromes.

When we look at autoimmune based findings of breast cancer; antibodies against P185 oncoprotein secreted from the Her/ neu-derived transmembrane protein in the serum of $50 \%$ of breast cancer patients were detected but could not be clinically meaningful because they were detected in healthy volunteers as well [11]. In addition, antibodies against anti-yo, anti-ri, anti$\mathrm{hu}$, anti-mA, and anti-amphiphysin have been associated with various neurological syndromes $[12,13]$. According to the general hypothesis of neurological paraneoplastic syndromes in breast cancer, degeneration of cell debris, which is turned on after the death of genetically altered tumor cells, is thought to be recognized by scavenger receptors, and that these proteins trigger the autoimmune response through the $\mathrm{T}$ and $\mathrm{B}$ cells in the lymph node [14]. Two nephrotic syndrome cases in the literature in association with breast cancer were reported to loss of their disease after cancer treatment [15]. However, we cannot find any association between breast cancer and autoimmune hypoparathyroidism in the literature.

The most common metastatic subtype of breast cancer to endocrine organs is lobular carcinoma. Among these, adrenal gland and pituitary gland metastases are most frequently seen [16]. In the differential diagnosis of the mass in the clivus, thickening of the pituitary infundibulum, nodularities in the cranial and pituitary MR images of the patient, metastatic malignancies have been recognized in addition to tuberculosis, sarcoidosis and autoimmune hypophysitis. The cause of hypocalcemia in this patient may have been an autoimmune process that causes destruction or hypofunction in the parathyroid gland as well as osteoblastic metastases. 


\section{Conclusion}

Although there are other reasons that complicate the clinical status in treatment-resistant hypocalcemia patients, it should be considered that there may be an underlying malignancy.

\section{References}

1. Schattner A, Dubin I, Huber R, Gelber M (2016) Hypocalcaemia of malignancy. Neth J Med 74(6): 231-239.

2. Underbjerg L, Sikjaer T, Mosekilde L, Rejnmark L (2015) The epidemiology of nonsurgical hypoparathyroidism in Denmark: a nationwide case finding study. J Bone Miner Res 30(9): 1738-1744.

3. Ferlay J, Soerjomataram I, Dikshit R, Eser S, Mathers C, et al. (2015) Cancer incidence and mortality worldwide: sources, methods and major patterns in Globocan 2012. Int J Cancer 136(5): E359-386.

4. Orvieto E, Maiorano E, Bottiglieri L, Maisonneuve P, Rotmensz N, et al (2008) Clinicopathologic characteristics of invasive lobular carcinoma of the breast: results of an analysis of 530 cases from a single institution. Cancer 113(7): 1511-1520.

5. Marx SJ (2000) Hyperparathyroid and hypoparathyroid disorders. The New England Journal of Medicine 343(25): 1863-1875.

6. Autio KA, Farooki A, Glezerman IG, Chan A, Schneider CW, et al. (2015) Severe hypocalcemia associated with denosumab in metastatic castration-resistant prostate cancer: risk factors and precautions for treating physicians. Clin Genitourin Cancer 13(4): e305-e309.

7. Smallridge RC, Wray HL, Schaaf M (1981) Hypocalcemia with osteoblastic metastases in patients with prostate carcinoma. A cause of secondary hyperparathyroidism. Am J Med 71(1): 184-188.
8. Hermus A, Beex L, van Liessum P, Pieters G, Smedts F, et al. (1988) Hypocalcemia due to osteoblastic metastases and diminished parathyroid reserve in a patient with advanced breast cancer. Klin Wochenschr 66(14): 643-646.

9. Paget $S$ (1989) The distribution of secondary growths in cancer of the breast. 1889. Cancer Metastasis Rev 8(2): 98-101.

10. Ibrahim T, Flamini E, Mercatali L, Sacanna E, Serra P, et al. (2010) Pathogenesis of osteoblastic metastases from prostate cancer. Cancer 116(6): 1406-1418.

11. Alexander Shifrin, Virginia LiVolsi, Svetlana Shifrin-Douglas, Min Zheng, Brian Erler, et al. (2015) Primary and metastatic parathyroid malignancies: a rare or underdiagnosed condition? The Journal of Clinical Endocrinology and Metabolism 100: E478-E481.

12. Rojas-Marcos I, Rousseau A, Keime-Guibert F, Reñé R, Cartalat-Carel S, et al. (2003) Spectrum of paraneoplastic neurological disorders in women with breast and gynecologic cancer. Medicine (Baltimore) 82(3): 216223.

13. Sahashi K, Sakai K, Mano K, Hirose G (2003) Anti-Ma2 antibody-related paraneoplastic limbic/brain stem encephalitis associated with breast cancer expressing Ma1, Ma2, and Ma3 mRNAs. J Neurol Neurosurg Psychiatry 74(9): 1332-1335.

14. Fanous I, Dillon P (2015) Paraneoplastic neurological complications of breast cancer. Exp Hematol Oncol 5: 29.

15. Kijima Y, Yoshinaka H, Owaki T, Nozaki T, Hamada T, et al. (2004) Breast cancer with nephrotic syndrome: report of two cases. Surgery today 34(9): 755-759.

16. Bumpers HL, Hassett JM, Penetrante RB, Hoover EL, Holyoke ED et al. (1993) Endocrine Organ Metastases in Subjects with Lobular Carcinoma of the Breast. Arch Surg 128(12): 1344-1347. 